\title{
Comparison of Long-Term Fertility and Bleeding Outcomes after Robotic-Assisted, Laparoscopic, and Abdominal Myomectomy
}

\author{
Rebecca Flyckt, Enrique Soto, Benjamin Nutter, and Tommaso Falcone
}

Obstetrics, Gynecology, and Women's Health Institute, Cleveland Clinic, Cleveland, OH, USA

Correspondence should be addressed to Rebecca Flyckt; flycktr@ccf.org

Received 31 July 2016; Revised 10 November 2016; Accepted 24 November 2016

Academic Editor: W. T. Creasman

Copyright ( 2016 Rebecca Flyckt et al. This is an open access article distributed under the Creative Commons Attribution License, which permits unrestricted use, distribution, and reproduction in any medium, provided the original work is properly cited.

\begin{abstract}
Background/Aims. To compare long-term fertility and bleeding outcomes of women who underwent robotic-assisted, laparoscopic, and abdominal myomectomy at our institution over a 15-year period. Methods. This was a retrospective cohort study of myomectomy patients 18-39 years old that had surgery between January 1995 and December 2009 at our institution. Long-term follow-up on fertility and bleeding outcomes was collected from the patient directly. The uterine fibroid symptom and quality of life survey was also administered to assess current bleeding patterns. Baseline characteristics were compared across groups. Univariable comparisons of fertility and bleeding outcomes based on surgical approach were made using analysis of variance, Kruskal-Wallis analysis of ranks, and Chi-square tests as appropriate. Results. 134/374 (36\%) subjects agreed to participate in the study. 81 subjects underwent an open procedure versus 28 and 25 subjects in the laparoscopic and robotic groups, respectively. Median follow-up after surgery was 8 years. $50 \%$ of patients desired pregnancy following surgery and, of those, $60 \%$ achieved spontaneous pregnancy; the spontaneous pregnancy rate did not differ between groups. Additionally, UFS-QOL scores and/or subscores did not differ between groups. Conclusion. There is no significant difference in long-term bleeding or fertility outcomes in robotic-assisted, laparoscopic, or abdominal myomectomy.
\end{abstract}

\section{Introduction}

Uterine fibroids are a common pathology among reproductive-aged women, causing abnormal uterine bleeding, pelvic discomfort, and at times infertility [1]. Fertility preserving surgical options for uterine fibroids includes robotic-assisted, laparoscopic, and abdominal (open) myomectomy. Open surgery via laparotomy was the original surgical technique described; however it results in a larger incision, more postoperative pain, and longer hospitalization than minimally invasive techniques [2-6]. Minimally invasive surgery using robotic assistance has been associated with decreased blood loss in comparison with laparoscopic myomectomy and open myomectomy, but longer operating times and increased cost compared with open myomectomy [6]. Most previous studies have focused on short-term peri- and postoperative variables; it has yet to be determined how mode of surgery affects longterm outcomes such as future fertility and bleeding patterns several years after surgery.
There is no prior study in the literature directly comparing long-term fertility and pregnancy outcomes after robotic-assisted, laparoscopic, and abdominal myomectomy, although several studies have evaluated two of these three surgical approaches side by side. A previous large study indicated no significant difference in pregnancy rate, abortion rate, preterm delivery, or cesarean section after myomectomy with laparotomy versus laparoscopy; however the population studied largely had preexisting infertility and follow-up was limited to 3 years [6]. The concern for increased risk of uterine rupture with minimally invasive myomectomy has been widely discussed but is thus far unsupported by the available data [7].

As with fertility and pregnancy outcomes, there are no studies directly comparing long-term bleeding patterns after robotic-assisted, laparoscopic, and open myomectomy. The uterine fibroid symptom and quality of life (UFS-QOL) questionnaire has been used previously to assess bleeding patterns and QOL indicators in patients treated for uterine 
fibroids $[8,9]$. This validated questionnaire is intended to assess bleeding symptoms as well as bleeding quality of life [10]. The UFS-QOL questionnaire consists of self-reports along a Likert scale graded from one to five which assesses symptom severity as well as subscales of different quality of life domains which may be adversely affected by fibroid symptoms (such as concern, activities, energy/mood, control, self-consciousness, and sexual function). Higher scores indicate more severe quality of life effects. A previous study demonstrated substantial improvements in UFS-QOL scores in women who underwent hysterectomy, myomectomy, or uterine artery embolization for treatment of uterine fibroids 12 months before, with the greatest improvements seen after hysterectomy [9].

The goal of this investigation was to define whether fertility outcomes and/or UFS-QOL scores differ after roboticassisted, laparoscopic, or abdominal myomectomy on longterm (up to 18 years) follow-up. Our primary objective was to determine the success in achieving a live birth in patients who desired a pregnancy after myomectomy. A secondary objective was to compare long-term bleeding patterns by mode of surgery. This is the first study to directly compare these three surgical approaches along long-term parameters. A finding of significant differences could guide surgeons in counseling reproductive-aged women regarding the optimal method of fertility-sparing surgery for uterine fibroids.

\section{Materials and Methods}

2.1. Study Population. Cases were identified through surgical billing codes within our institution. From identified cases, a list was generated of 374 nonhysteroscopic myomectomies that had been performed between January 1995 and December 2009 on women aged 18-39. These patients were then divided into three groups based on whether they underwent robotic-assisted, laparoscopic, or abdominal myomectomy. Operative notes were reviewed to confirm the surgical approach. The robotic-assisted group underwent myomectomy using the da Vinci surgical system. The laparoscopic and abdominal groups underwent myomectomy using established surgical procedures [11]. Exclusion criteria included age $(<18$ or $\geq 40)$, history of primary ovarian insufficiency or tubal factor infertility, or history of a bleeding disorder.

2.2. Data Collection and Analysis. This cohort study was approved by the Cleveland Clinic Institutional Review Board. We received approval to contact patients by mail and/or email to complete a survey regarding details of their surgery as well as fertility history after myomectomy and current bleeding patterns. Patients then received a follow-up phone call to complete the phone survey if desired. Patients also had the option of submitting their responses electronically through a link to a secure internet survey if preferred. Preliminary findings from this research were presented at the American Society for Reproductive Medicine meeting in 2012 [12].

Baseline characteristics such as age, race, body mass index, marital status, educational level, prior parity, and income were collected. The UFS-QOL survey was included and information regarding need for additional menorrhagia
TABLE 1: Overall demographics.

\begin{tabular}{|c|c|c|}
\hline Factor & $N$ & Statistics \\
\hline Age at surgery ${ }^{a}$ & 133 & $34 \pm 4.3$ \\
\hline \multicolumn{3}{|l|}{ Race/ethnicity ${ }^{\mathrm{b}}$} \\
\hline White/Caucasian & 74 & 56.1 \\
\hline African American & 43 & 32.6 \\
\hline American Indian & 0 & 0 \\
\hline Asian Indian & 4 & 3 \\
\hline Latino/Hispanic & 8 & 6.1 \\
\hline Other & 3 & 2.3 \\
\hline $\mathrm{BMI}^{\mathrm{c}}$ & 133 & $27.5[16.5,55.8]$ \\
\hline \multicolumn{3}{|l|}{ Current marital status $^{\mathrm{b}}$} \\
\hline Married & 78 & 59.5 \\
\hline Single, never married & 42 & 32.1 \\
\hline Separated & 0 & 0 \\
\hline Divorced & 10 & 7.6 \\
\hline Widowed & 1 & 0.8 \\
\hline \multicolumn{3}{|c|}{ Highest level of education completed ${ }^{\mathrm{b}}$} \\
\hline Less than junior high & 0 & 0 \\
\hline Junior high & 1 & 0.8 \\
\hline Partial high school & 0 & 0 \\
\hline High school graduate & 8 & 6.2 \\
\hline Partial college & 29 & 22.5 \\
\hline College graduate & 47 & 36.4 \\
\hline Graduate degree & 44 & 34.1 \\
\hline Years since surgery $^{c}$ & 133 & $8[4,18]$ \\
\hline \multicolumn{3}{|l|}{ Surgery type $\mathrm{e}^{\mathrm{b}}$} \\
\hline Laparoscopic & 28 & 20.9 \\
\hline Open & 81 & 60.4 \\
\hline Robotic & 25 & 18.7 \\
\hline
\end{tabular}

${ }^{\mathrm{a}}$ Mean $\pm \mathrm{SD} .{ }^{\mathrm{b}}$ Percentage. ${ }^{\mathrm{c}}$ Median [Min, Max].

treatment or repeat surgery, such as hysterectomy, was collected. Fertility outcomes, desire for pregnancy after surgery, pregnancies after surgery, and the use and results of fertility treatments were collected. Additionally, pregnancy complications, mode of delivery, and obstetrical outcomes were collected.

Baseline characteristics were described and compared across groups. Univariable comparisons of fertility and bleeding outcomes based on surgical approach were made using analysis of variance for normal data, Kruskal-Wallis analysis of ranks for nonnormal data, and Chi-square tests as appropriate. Normality was determined by visual inspection of histograms and QQ plots. Data were stored in a REDCap database and analyses were performed using $\mathrm{R}$ version 3.1.0 (2014-04-10).

\section{Results}

3.1. Baseline Statistics. Table 1 presents a summary of subject demographics. Thirty-six percent (134/374) of identified patients participated in the study. The robotic-assisted, laparoscopic, and abdominal myomectomy groups contained 
TABLE 2: Demographics by surgery type.

\begin{tabular}{|c|c|c|c|c|c|c|c|c|}
\hline \multirow{2}{*}{ Factor } & \multirow{2}{*}{ Total } & \multicolumn{2}{|c|}{ Laparoscopic } & \multicolumn{2}{|c|}{ Open } & \multicolumn{2}{|c|}{ Robotic } & \multirow{2}{*}{$p$ value } \\
\hline & & $N$ & Statistics & $N$ & Statistics & $N$ & Statistics & \\
\hline Age at surgery ${ }^{a}$ & 133 & 28 & $33.5 \pm 4.4$ & 80 & $34.1 \pm 4.5$ & 25 & $34 \pm 3.8$ & $0.77^{\mathrm{A}}$ \\
\hline Race/ethnicity ${ }^{\mathrm{b}}$ & 132 & & & & & & & $0.013^{\mathrm{C}}$ \\
\hline White/Caucasian & 74 & 20 & 71.4 & 42 & 52.5 & 12 & 50 & \\
\hline African American & 43 & 4 & 14.3 & 33 & 41.2 & 6 & 25 & \\
\hline American Indian & 0 & 0 & 0 & 0 & 0 & 0 & 0 & \\
\hline Asian Indian & 4 & 1 & 3.6 & 2 & 2.5 & 1 & 4.2 & \\
\hline Latino/Hispanic & 8 & 2 & 7.1 & 1 & 1.2 & 5 & 20.8 & \\
\hline Other & 3 & 1 & 3.6 & 2 & 2.5 & 0 & 0 & \\
\hline $\mathrm{BMI}^{\mathrm{c}}$ & 133 & 28 & $\begin{array}{c}25.2 \\
{[20.3,48.7]}\end{array}$ & 80 & $\begin{array}{c}28.2 \\
{[16.5,55.8]}\end{array}$ & 25 & $\begin{array}{c}29.1 \\
{[19.3,43.6]}\end{array}$ & $0.20^{\mathrm{K}}$ \\
\hline Current marital status $^{\mathrm{b}}$ & 131 & & & & & & & $0.33^{\mathrm{C}}$ \\
\hline Married & 78 & 21 & 77.8 & 44 & 55.7 & 13 & 52 & \\
\hline Single, never married & 42 & 5 & 18.5 & 26 & 32.9 & 11 & 44 & \\
\hline Separated & 0 & 0 & 0 & 0 & 0 & 0 & 0 & \\
\hline Divorced & 10 & 1 & 3.7 & 8 & 10.1 & 1 & 4 & \\
\hline Widowed & 1 & 0 & 0 & 1 & 1.3 & 0 & 0 & \\
\hline $\begin{array}{l}\text { Highest level of education } \\
\text { completed }^{\mathrm{b}}\end{array}$ & 129 & & & & & & & $0.43^{\mathrm{C}}$ \\
\hline Less than junior high & 0 & 0 & 0 & 0 & 0 & 0 & 0 & \\
\hline Junior high & 1 & 1 & 3.7 & 0 & 0 & 0 & 0 & \\
\hline Partial high school & 0 & 0 & 0 & 0 & 0 & 0 & 0 & \\
\hline High school graduate & 8 & 3 & 11.1 & 5 & 6.3 & 0 & 0 & \\
\hline Partial college & 29 & 5 & 18.5 & 19 & 24.1 & 5 & 21.7 & \\
\hline College graduate & 47 & 8 & 29.6 & 31 & 39.2 & 8 & 34.8 & \\
\hline Graduate degree & 44 & 10 & 37 & 24 & 30.4 & 10 & 43.5 & \\
\hline Parity $^{c}$ & 134 & 28 & $0[0,4]$ & 81 & $0[0,3]$ & 25 & $0[0,2]$ & $0.21^{\mathrm{K}}$ \\
\hline Years since surgery $^{c}$ & 133 & 28 & $7[4,16]$ & 80 & $11[5,18]$ & 25 & $4[4,5]$ & $<0.001^{\mathrm{K}}$ \\
\hline
\end{tabular}

${ }^{\mathrm{a}}$ Mean \pm SD. ${ }^{\mathrm{b}}$ Percentage. ${ }^{\mathrm{c}}$ Median [Min, Max].

${ }^{\text {A }}$ Analysis of variance.

${ }^{\mathrm{C}}$ Pearson's Chi-squared test.

${ }^{\mathrm{K}}$ Kruskal-Wallis rank sum test.

25 (19\%), 28 (21\%), and 81 subjects (60\%), respectively. Mean age at the time of surgery was $34 \pm 4.3$. Median follow-up after surgery was 8 years and mean age at time of the survey was $42.9 \pm 6.4$. Subjects were predominantly Caucasian $(56 \%)$ or African American (33\%) and overweight with a median BMI of 27.5. Subjects were most likely to be married (60\%) and educated, with $93 \%$ having at least partial college experience.

Subject demographics were also compared by surgery type (Table 2). In this analysis, age at the time of survey and years since surgery were significantly different, with the robotic group having significantly younger age at the time of survey (41 versus 45 versus 38 years old, $p<0.001$ ) and median years since surgery (7 versus 11 versus 4 years, $p<$ $0.001)$. Additionally, race/ethnicity appeared to vary significantly by surgery subgroup $(p=0.013)$, with larger percentages of Latino/Hispanic patients in the robotic surgery group, African American patients in the open group, and Caucasian patients in the laparoscopic group.
3.2. Surgical Outcomes. Table 3 illustrates long-term outcomes for reoperation and ongoing treatments for bleeding by surgery subtype. The overall risk of postoperative complications such as blood transfusion $(8.2 \%)$, infection $(3.7 \%)$, hernia $(0.7 \%)$, and thromboembolism $(2.2 \%)$ was low in all the three groups and there were no statistically significant differences between surgical subtypes. More patients required an additional surgery for uterine fibroids from the open surgery group (16\%) than from the laparoscopic or robotic myomectomy groups ( $11 \%$ and $8 \%$, resp.); this difference was not statistically significant however. Subsequent hysterectomy for menorrhagia was performed in $14.3 \%$ versus $19.8 \%$ versus $4.2 \%$ of patients in the laparoscopic, open, and robotic myomectomy groups, respectively. Again, this was not a significant difference between subgroups.

3.3. Fertility and Obstetric Outcomes. Fertility outcomes were compared between groups (Table 4). In our study population, 
TABLE 3: Long-term outcomes for reoperation and bleeding by surgery type.

\begin{tabular}{|c|c|c|c|c|c|c|c|c|}
\hline \multirow{2}{*}{ Factor } & \multirow{2}{*}{ Total } & \multicolumn{2}{|c|}{ Laparoscopic } & \multicolumn{2}{|c|}{ Open } & \multicolumn{2}{|c|}{ Robotic } & \multirow{2}{*}{$p$ valu } \\
\hline & & $N$ & Statistics & $N$ & Statistics & $N$ & Statistics & \\
\hline Fibroid surgeries after fibroid surgery (not including hysterectomy) ${ }^{\mathrm{a}}$ & 133 & & & & & & & $0.061^{\mathrm{C}}$ \\
\hline None & 115 & 25 & 89.3 & 68 & 84 & 22 & 91.7 & \\
\hline 1 & 13 & 0 & 0 & 11 & 13.6 & 2 & 8.3 & \\
\hline 2 & 5 & 3 & 10.7 & 2 & 2.5 & 0 & 0 & \\
\hline 3 & 0 & 0 & 0 & 0 & 0 & 0 & 0 & \\
\hline 4 or more & 0 & 0 & 0 & 0 & 0 & 0 & 0 & \\
\hline Hysterectomy for bleeding after initial fibroid surgery ${ }^{a}$ & 133 & & & & & & & $0.18^{\mathrm{C}}$ \\
\hline Yes & 21 & 4 & 14.3 & 16 & 19.8 & 1 & 4.2 & \\
\hline No & 112 & 24 & 85.7 & 65 & 80.2 & 23 & 95.8 & \\
\hline Birth control pills ${ }^{\mathrm{a}}$ & 134 & & & & & & & $0.20^{\mathrm{C}}$ \\
\hline Yes & 14 & 3 & 10.7 & 6 & 7.4 & 5 & 20 & \\
\hline No & 120 & 25 & 89.3 & 75 & 92.6 & 20 & 80 & \\
\hline Depo provera $^{a}$ & 134 & & & & & & & $0.51^{\mathrm{C}}$ \\
\hline Yes & 2 & 0 & 0 & 2 & 2.5 & 0 & 0 & \\
\hline No & 132 & 28 & 100 & 79 & 97.5 & 25 & 100 & \\
\hline IUD (intrauterine device) ${ }^{\mathrm{a}}$ & 134 & & & & & & & $0.26^{\mathrm{C}}$ \\
\hline Yes & 4 & 0 & 0 & 4 & 4.9 & 0 & 0 & \\
\hline No & 130 & 28 & 100 & 77 & 95.1 & 25 & 100 & \\
\hline NSAIDs $^{\mathrm{a}}$ & 134 & & & & & & & $0.83^{\mathrm{C}}$ \\
\hline Yes & 7 & 1 & 3.6 & 5 & 6.2 & 1 & 4 & \\
\hline No & 127 & 27 & 96.4 & 76 & 93.8 & 24 & 96 & \\
\hline
\end{tabular}

${ }^{\text {a Percentage. }}$

${ }^{\mathrm{C}}$ Pearson's Chi-squared test.

$67 / 134(50 \%)$ of subjects desired and attempted pregnancy after myomectomy. 40/67 (60\%) of women desiring pregnancy achieved a total of 82 pregnancies which resulted in 51 live births. For women who attempted pregnancy, the highest pregnancy rate was in the abdominal group (66.7\%) versus $50 \%$ of women conceiving in the robotic and laparoscopic groups; this comparison was not statistically significant. Similarly, there was no significant difference in the use of fertility treatments or successful pregnancy with fertility treatments. $25 \%(n=17)$ of women desiring fertility after myomectomy underwent subsequent fertility treatments, and the majority of those patients $(59 \%, n=10)$ did achieve a pregnancy.

Miscarriage rates were up to $15 \%$ but did not differ significantly by surgery subtype. Uterine rupture was not reported in any group. Ninety percent of live births were delivered by cesarean section, with previous fibroid surgery cited as the most common reason (31/36 patients) for mode of delivery.

3.4. Bleeding Outcomes. Most surveyed patients (65\%) had ongoing menses, with $35 \%$ having undergone either natural or surgical menopause (i.e., related to undergoing hysterectomy). Bleeding patterns for patients who continued to have menses were compared by UFS-QOL scores. Scores were compared as raw scores and also as standardized scores. Standardized scores were calculated on a scale for 0 to 1 where 0 represented the smallest possible subscore and 1 represented the largest possible subscore. As demonstrated in Table 5, there were no differences between scores and/or subscores for any surgical group. To account for the relative recency of the robotic myomectomies, this finding was verified using a linear model of UFS-QOL scores by surgery type controlling for number of years since surgery (Table 6).

\section{Discussion}

This is the first study to directly compare both minimally invasive approaches (robotic-assisted and laparoscopic) against open myomectomy for long-term reproductive outcomes such as fertility, miscarriage, and pregnancy complications. A search of MEDLINE (English language; 19802014; search terms: "robotic myomectomy" and "fertility") immediately prior to manuscript submission revealed no other similar studies. Additionally, the focus on long-term rather than short-term outcomes is unique. Most previous studies of minimally invasive myomectomy have assessed peri- and postoperative parameters such as blood loss, duration of surgery, postoperative pain, or days of hospitalization. In fact, a previous analysis of short-term surgical variables in a similar cohort from our group demonstrated decreased blood loss and length of stay with robotic myomectomy versus conventional approaches with comparable myoma size, number, and location [6]. The superiority of minimally invasive myomectomy for specific short-term parameters is now well documented. The data presented here contributes to a small but growing body of literature that indicates 
TABLE 4: Long-term fertility outcomes by surgery type.

\begin{tabular}{|c|c|c|c|c|c|c|c|c|}
\hline \multirow{2}{*}{ Factor } & \multirow{2}{*}{ Total } & \multicolumn{2}{|c|}{ Laparoscopic } & \multicolumn{2}{|c|}{ Open } & \multicolumn{2}{|c|}{ Robotic } & \multirow{2}{*}{$p$ value } \\
\hline & & $N$ & Statistics & $N$ & Statistics & $N$ & Statistics & \\
\hline Attempted pregnancy $^{\mathrm{a}}$ & 134 & & & & & & & $0.18^{\mathrm{C}}$ \\
\hline Yes & 67 & 10 & 35.7 & 42 & 51.9 & 15 & 60 & \\
\hline No & 67 & 18 & 64.3 & 39 & 48.1 & 10 & 40 & \\
\hline Achieved spontaneous pregnancy ${ }^{\mathrm{a}}$ & 67 & & & & & & & $0.39^{\mathrm{C}}$ \\
\hline Yes & 40 & 9 & 50 & 26 & 66.7 & 5 & 50 & \\
\hline No & 27 & 9 & 50 & 13 & 33.3 & 5 & 50 & \\
\hline Fertility assistance/treatments after fibroid surgery ${ }^{a}$ & 66 & & & & & & & $0.71^{\mathrm{C}}$ \\
\hline Yes & 17 & 6 & 33.3 & 8 & 21.1 & 3 & 30 & \\
\hline No and not planning treatments & 44 & 10 & 55.6 & 28 & 73.7 & 6 & 60 & \\
\hline No, but planning treatments in the future & 5 & 2 & 11.1 & 2 & 5.3 & 1 & 10 & \\
\hline Pregnant using fertility treatments ${ }^{\mathrm{a}}$ & 17 & & & & & & & $0.78^{\mathrm{C}}$ \\
\hline Yes & 10 & 4 & 66.7 & 4 & 50 & 2 & 66.7 & \\
\hline No & 7 & 2 & 33.3 & 4 & 50 & 1 & 33.3 & \\
\hline Had miscarriage $^{a}$ & 134 & & & & & & & $0.12^{\mathrm{C}}$ \\
\hline Yes & 16 & 4 & 14.3 & 12 & 14.8 & 0 & 0 & \\
\hline No & 118 & 24 & 85.7 & 69 & 85.2 & 25 & 100 & \\
\hline Complications during pregnancy or delivery ${ }^{\mathrm{a}}$ & 134 & & & & & & & $0.52^{\mathrm{C}}$ \\
\hline Yes & 13 & 4 & 14.3 & 6 & 7.4 & 3 & 12 & \\
\hline No & 121 & 24 & 85.7 & 75 & 92.6 & 22 & 88 & \\
\hline Reason for C-section ${ }^{a}$ & 36 & & & & & & & $0.015^{\mathrm{C}}$ \\
\hline Other & 3 & 0 & 0 & 1 & 5 & 2 & 40 & \\
\hline Prior fibroid surgery & 31 & 9 & 81.8 & 19 & 95 & 3 & 60 & \\
\hline Wanted a repeat CS & 2 & 2 & 18.2 & 0 & 0 & 0 & 0 & \\
\hline Live birth ${ }^{\mathrm{a}}$ & 40 & & & & & & & $0.30^{\mathrm{C}}$ \\
\hline Yes & 36 & 9 & 100 & 22 & 84.6 & 5 & 100 & \\
\hline No & 4 & 0 & 0 & 4 & 15.4 & 0 & 0 & \\
\hline
\end{tabular}

${ }^{\mathrm{a}}$ Percentage.

${ }^{\mathrm{C}}$ Pearson's Chi-squared test.

TABLE 5: UFS-QOL by surgery type.

\begin{tabular}{|c|c|c|c|c|c|c|c|c|}
\hline \multirow{2}{*}{ Factor } & \multirow{2}{*}{ Total } & \multicolumn{2}{|c|}{ Laparoscopic } & \multicolumn{2}{|c|}{ Open } & \multicolumn{2}{|c|}{ Robotic } & \multirow{2}{*}{$p$ value } \\
\hline & & $N$ & Statistics & $N$ & Statistics & $N$ & Statistics & \\
\hline Symptom subscore $^{\mathrm{a}}$ & 87 & 18 & $12.5[8,36]$ & 49 & $15[8,36]$ & 20 & $11[8,26]$ & $0.13^{\mathrm{K}}$ \\
\hline Standardized symptom subscore ${ }^{\mathrm{a}}$ & 87 & 18 & $0.1[0,0.9]$ & 49 & $0.2[0,0.9]$ & 20 & $0.1[0,0.6]$ & $0.13^{\mathrm{K}}$ \\
\hline Concern subscore $^{a}$ & 87 & 18 & $6[5,19]$ & 49 & $8[5,25]$ & 20 & $5[5,22]$ & $0.21^{\mathrm{K}}$ \\
\hline Standardized concern subscore ${ }^{\mathrm{a}}$ & 87 & 18 & $1[0.3,1]$ & 49 & $0.8[0,1]$ & 20 & $1[0.2,1]$ & $0.21^{\mathrm{K}}$ \\
\hline Activities subscore $^{\mathrm{a}}$ & 89 & 18 & $7[7,22]$ & 50 & $8[7,30]$ & 21 & $8[7,20]$ & $0.28^{\mathrm{K}}$ \\
\hline Standardized activities subscore ${ }^{a}$ & 89 & 18 & $1[0.5,1]$ & 50 & $1[0.2,1]$ & 21 & $1[0.5,1]$ & $0.28^{\mathrm{K}}$ \\
\hline Energy subscore $^{\mathrm{a}}$ & 87 & 18 & $8.5[7,32]$ & 48 & $9[7,31]$ & 21 & $7[7,30]$ & $0.75^{\mathrm{K}}$ \\
\hline Standardized energy subscore ${ }^{\mathrm{a}}$ & 87 & 18 & $0.9[0.1,1]$ & 48 & $0.9[0.1,1]$ & 21 & $1[0.2,1]$ & $0.75^{\mathrm{K}}$ \\
\hline Control subscore $^{\mathrm{a}}$ & 87 & 18 & $5.5[5,16]$ & 48 & $5.5[5,20]$ & 21 & $5[5,19]$ & $0.84^{\mathrm{K}}$ \\
\hline Standardized control subscore ${ }^{\mathrm{a}}$ & 87 & 18 & $1[0.4,1]$ & 48 & $1[0.2,1]$ & 21 & $1[0.3,1]$ & $0.84^{\mathrm{K}}$ \\
\hline Self-conscious subscore ${ }^{\mathrm{a}}$ & 89 & 18 & $3[3,15]$ & 50 & $4[3,13]$ & 21 & $4[3,13]$ & $0.32^{\mathrm{K}}$ \\
\hline Standardized self-conscious subscore ${ }^{\mathrm{a}}$ & 89 & 18 & $1[0,1]$ & 50 & $0.9[0.2,1]$ & 21 & $0.9[0.2,1]$ & $0.32^{\mathrm{K}}$ \\
\hline Sexual function subscore ${ }^{a}$ & 87 & 18 & $2[2,10]$ & 48 & $3[2,10]$ & 21 & $2[2,8]$ & $0.13^{\mathrm{K}}$ \\
\hline Standardized sexual function subscore ${ }^{a}$ & 87 & 18 & $1[0,1]$ & 48 & $0.9[0,1]$ & 21 & $1[0.2,1]$ & $0.13^{\mathrm{K}}$ \\
\hline Total score $^{\mathrm{a}}$ & 86 & 18 & $37.5[29,97]$ & 48 & $42.5[29,121]$ & 20 & $34[29,107]$ & $0.32^{\mathrm{K}}$ \\
\hline Standardized total score ${ }^{\mathrm{a}}$ & 86 & 18 & $0.9[0.4,1]$ & 48 & $0.9[0.2,1]$ & 20 & $1[0.3,1]$ & $0.32^{\mathrm{K}}$ \\
\hline
\end{tabular}

${ }^{a}$ Median [Min, Max].

${ }^{\mathrm{K}}$ Kruskal-Wallis rank sum test. 
TABLE 6: Linear model for total UFS-QOL score.

\begin{tabular}{|c|c|c|c|c|}
\hline Factor & Level & Beta & 95\% confidence interval & $p$ value $(T)$ \\
\hline Intercept & & 53.0 & $(36.7,69.4)$ & $<0.001$ \\
\hline \multirow[t]{2}{*}{ Surgery type } & Open versus laparoscopic & 13.3 & $(-1.5,28.1)$ & 0.073 \\
\hline & Robotic versus laparoscopic & -1.5 & $(-18,15)$ & 0.86 \\
\hline Years since surgery & & -1.3 & $(-3,0.4)$ & 0.12 \\
\hline Observations: 85 & & & & $R^{2}: 0.05$ \\
\hline Deg. of freedom: 3 & & & & $R^{2}$ _adj: 0.02 \\
\hline
\end{tabular}

equivalence of minimally invasive myomectomy as compared to traditional abdominal myomectomy over long-term follow-up. Finally, this research compares both bleeding outcomes and fertility outcomes after different surgical approaches, which is a broader set of endpoints than prior myomectomy studies that do not include menstrual data.

Our primary goal was to determine the success in achieving a live birth in patients who desired a pregnancy after myomectomy. The finding of no difference in spontaneous pregnancy rates is consistent with prior studies $[5,13]$. The Cochrane database review from 2012 included only two randomized trials and concluded that there is no difference in subsequent fertility for myomectomy performed via laparotomy or laparoscopy [14]. There was no difference in live birth rate, miscarriage rate, or cesarean delivery rate. The Cochrane review did not include robotic myomectomy and was limited by the small number of studies and number of patients included in their dataset. A recent case series of robotic myomectomy for women with deep intramural myomas showed a similar pregnancy rate of $68 \%$ after surgery, although many of these pregnancies were with assisted reproductive technologies [15]. As in the Cochrane review, miscarriages were reported in our study but did not differ by surgical approach with the majority of pregnancies progressing to live births. The cesarean rate reported in our dataset was high; however this is not unexpected given the increasing rates of cesarean section overall and the litigious culture of obstetrics in the United States.

There were no cases of uterine rupture in our study population with any surgical approach. In the past there has been concern for uterine rupture following minimally invasive myomectomy; a review of the available data is reassuring. Although some have suggested that inadequate closure of the myometrial defect or overreliance on electrocautery would weaken the uterine wall, a large multicenter trial of 2,050 laparoscopic myomectomies reported only a single case of uterine rupture [16]. Another smaller study of laparoscopic myomectomy showed no rupture in a series of 158 recorded pregnancies [17]. A 2013 study of robotic myomectomy reported a uterine rupture rate of $1 \%$ in 127 pregnancies [18]. These risks seem similar to the reported risk of uterine rupture after abdominal myomectomy or prior low transverse cesarean delivery.

Our secondary objective for this study was to determine whether quality of life related to bleeding patterns differed based on route of surgery. The UFS-QOL questionnaire data is reassuring. Although some patients continue to report abnormal uterine bleeding on long-term follow-up, there is no significant difference between surgical subgroups. Rates of reoperation or hysterectomy are similar to that reported in the literature following open myomectomy [19] and do not differ based on minimally invasive versus open approach in our group of patients.

The strengths of this study are the long-term follow-up, the three surgical approaches compared, and the multiple endpoints examined. This is a novel contribution to the literature regarding myomectomy and several authors have cited a need for this type of long-term outcome data [20, 21]. Many prior publications are case series from an individual surgeon at a single hospital reporting on relatively small numbers of patients. In general, these reports focus on one approach, for example, a surgeon's case series of robotic myomectomy. Very few studies have examined the long-term outcomes of robotic myomectomy due to recent adoption of the technique. Finally, the UFS-QOL was useful as a standardized, validated tool for the comparison of bleeding patterns following surgery. Most importantly, it assessed how significantly a patient's bleeding patterns impacted her current quality of life, which is perhaps the most important goal of fibroid surgery performed for abnormal uterine bleeding.

This work is not without limitations. It is a retrospective analysis based on patient recollection. This type of study design has inherent biases and information given by patients (aside from type of surgery performed) was not verified in the medical record. As indicated by the recent Cochrane review, additional randomized trials comparing surgical approaches would be valuable; however, for several reasons a randomized comparison of robotic-assisted, laparoscopic, and open myomectomy may not be ever be attempted. Further, there was a limited response rate to this survey (36\%). Although this was lower than anticipated, it is not unusual for studies of this nature. The majority of the original 374 patients had outdated contact information in the hospital database and could not be reached by either mail or email for the purposes of study recruitment. It is possible that those who were available for contact represent a different sample than those who could not be reached and may potentially have had more favorable outcomes with better access to fertility treatments.

Further, there were baseline differences in ethnic subgroup representation between the laparoscopic, open, and robotic groups; most notably, there were a high percentage of African American patients in the open surgery group. As African American women may have a higher burden of fibroid disease, there may have been larger uterine size 
and number of fibroids in the open surgery group. This difference poses potential bias to the study. The robotic and laparoscopic groups contained smaller numbers of patients than the open surgery group and appeared reflective of the total cohort of surgeries over 15 years. This is similar to the overall distribution of surgical subgroups for this cohort described in our previous report comparing shortterm outcomes between approaches [6]. Finally, the duration of follow-up for the robotic group is small due to the more recent adoption of this technique. Review of the included robotic cases confirmed that they were performed several years after robotic myomectomy was adopted at our institution and by experienced robotic surgeons; therefore, despite the smaller numbers, we believe that this data is accurate and would not be biased by the learning curve associated with acquiring robotic proficiency. Longer-term studies of robotic myomectomy outcomes are still desirable.

\section{Conclusions}

Compared with the standard open myomectomy technique, minimally invasive robotic and laparoscopic myomectomy appear to achieve similar outcomes over long-term followup. Both fertility and pregnancy outcomes as well as bleeding patterns are similar across surgical approaches. These data begin to address an important gap in our current literature and add to the overall supportive data surrounding minimally invasive surgical approaches to myomectomy. Reassuring long-term data combined with favorable comparisons of periand postoperative outcomes should prompt consideration of minimally invasive myomectomy whenever possible.

Tables. Numeric variables are summarized by mean and standard deviation when they appear to have a normal distribution. For nonnormally appearing data, summaries are given as median and interquartile range. Categorical values are summarized by frequency and percentage. All comparisons are univariable and are performed by analysis of variance (for normal data), Kruskal-Wallis analysis of ranks (nonnormal data), and Chi-square tests. Normality is determined by visual inspection of histograms and QQ plots. Data were stored in a REDCap database and analyses are performed using R version 3.1.0 (2014-04-10).

\section{Competing Interests}

The authors report no conflict of interests.

\section{Acknowledgments}

The authors wish to acknowledge Dr. Stephen Zimberg from Cleveland Clinic Florida for his support and significant contribution of patients to the study.

\section{References}

[1] E. A. Stewart, “Uterine fibroids," Lancet, vol. 357, no. 9252, pp. 293-298, 2001.

[2] T. Falcone and M. A. Bedaiwy, "Minimally invasive management of uterine fibroids," Current Opinion in Obstetrics and
Gynecology, vol. 14, no. 4, pp. 401-407, 2002.

[3] V. Mais, S. Ajossa, S. Guerriero, M. Mascia, E. Solla, and G. B. Melis, "Laparoscopic versus abdominal myomectomy: a prospective, randomized trial to evaluate benefits in early outcome," American Journal of Obstetrics and Gynecology, vol. 174, no. 2, pp. 654-658, 1996.

[4] M. Malzoni, M. Rotondi, C. Perone et al., "Fertility after laparoscopic myomectomy of large uterine myomas: operative technique and preliminary results," European Journal of Gynaecological Oncology, vol. 24, no. 1, pp. 79-82, 2003.

[5] R. Seracchioli, S. Rossi, F. Govoni et al., "Fertility and obstetric outcome after laparoscopic myomectomy of large myomata: a randomized comparison with abdominal myomectomy," Human Reproduction, vol. 15, no. 12, pp. 2663-2668, 2000.

[6] E. E. Barakat, M. A. Bedaiwy, S. Zimberg, B. Nutter, M. Nosseir, and T. Falcone, "Robotic-assisted, laparoscopic, and abdominal myomectomy: a comparison of surgical outcomes," Obstetrics \& Gynecology, vol. 117, no. 2, part 1, pp. 256-265, 2011.

[7] S. T. Lipskind and A. R. Gargiulo, "Computer-assisted laparoscopy in fertility preservation and reproductive surgery," Journal of Minimally Invasive Gynecology, vol. 20, no. 4, pp. 435-445, 2013.

[8] G. Harding, K. S. Coyne, C. L. Thompson, and J. B. Spies, "The responsiveness of the uterine fibroid symptom and healthrelated quality of life questionnaire (UFS-QOL)," Health and Quality of Life Outcomes, vol. 6, article no. 99, 2008.

[9] J. B. Spies, L. D. Bradley, R. Guido, G. L. Maxwell, B. A. Levine, and K. Coyne, "Outcomes from leiomyoma therapies: comparison with normal controls," Obstetrics and Gynecology, vol. 116, no. 3, pp. 641-652, 2010.

[10] J. B. Spies, K. Coyne, N. Guaou Guaou, D. Boyle, K. SkyrnarzMurphy, and S. M. Gonzalves, "The UFS-QOL, a new diseasespecific symptom and health-related quality of life questionnaire for leiomyomata," Obstetrics and Gynecology, vol. 99, no. 2, pp. 290-300, 2002.

[11] T. Falcone and W. H. Parker, "Surgical management of leiomyomas for fertility or uterine preservation," Obstetrics and Gynecology, vol. 121, no. 4, pp. 856-868, 2013.

[12] R. Flyckt, E. Soto, B. Nutter, and T. Falcone, "Comparison of long term fertility and bleeding outcomes after robotic, laparoscopic, and open myomectomy," Fertility and Sterility, vol. 98, no. 3, p. S37, 2012.

[13] S. Campo, V. Campo, and P. Gambadauro, "Reproductive outcome before and after laparoscopic or abdominal myomectomy for subserous or intramural myomas," European Journal of Obstetrics Gynecology and Reproductive Biology, vol. 110, no. 2, pp. 215-219, 2003.

[14] M. Metwally, Y. C. Cheong, and A. W. Horne, "Surgical treatment of fibroids for subfertility," The Cochrane Database of Systematic Reviews, vol. 11, Article ID CD003857, 2012.

[15] C. Lönnerfors and J. Persson, "Pregnancy following robotassisted laparoscopic myomectomy in women with deep intramural myomas," Acta Obstetricia et Gynecologica Scandinavica, vol. 90, no. 9, pp. 972-977, 2011.

[16] O. Sizzi, A. Rossetti, M. Malzoni et al., "Italian multicenter study on complications of laparoscopic myomectomy," Journal of Minimally Invasive Gynecology, vol. 14, no. 4, pp. 453-462, 2007.

[17] R. Seracchioli, L. Manuzzi, F. Vianello et al., "Obstetric and delivery outcome of pregnancies achieved after laparoscopic myomectomy," Fertility and Sterility, vol. 86, no. 1, pp. 159-165, 2006. 
[18] M. C. Pitter, A. R. Gargiulo, L. M. Bonaventura, J. Stefano Lehman, and S. S. Srouji, "Pregnancy outcomes following robotassisted myomectomy," Human Reproduction, vol. 28, no. 1, pp. 99-108, 2013.

[19] V. C. Buttram Jr. and R. C. Reiter, "Uterine leiomyomata: etiology, symptomatology, and management," Fertility and Sterility, vol. 36, no. 4, pp. 433-445, 1981.

[20] M. Carbonnel, J. Goetgheluck, A. Frati, M. Even, and J. M. Ayoubi, "Robot-assisted laparoscopy for infertility treatment: current views," Fertility and Sterility, vol. 101, no. 3, pp. 621-626, 2014.

[21] J. Pundir, V. Pundir, R. Walavalkar, K. Omanwa, G. Lancaster, and S. Kayani, "Robotic-assisted laparoscopic vs abdominal and laparoscopic myomectomy: systematic review and meta-analysis," Journal of Minimally Invasive Gynecology, vol. 20, no. 3, pp. 335-345, 2013. 


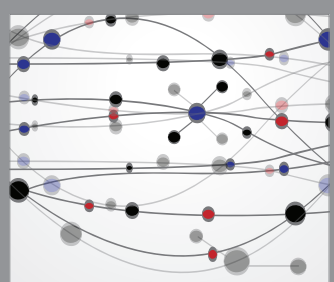

The Scientific World Journal
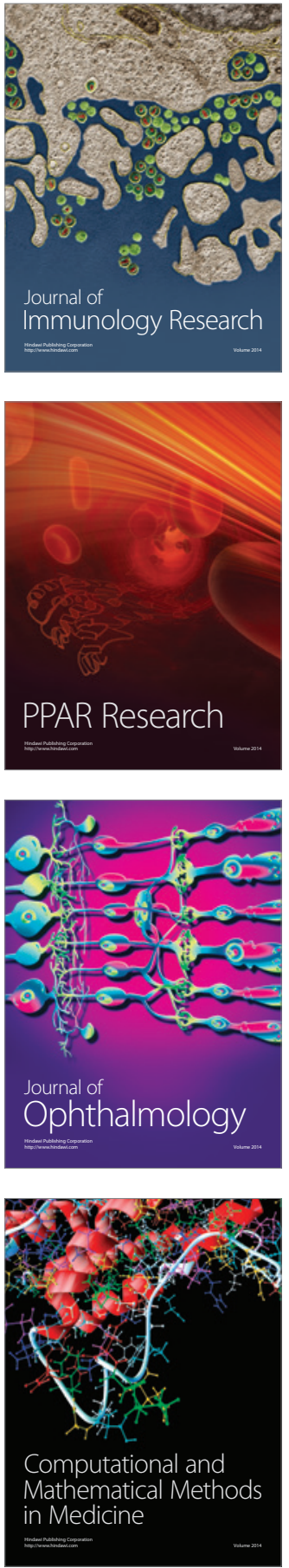

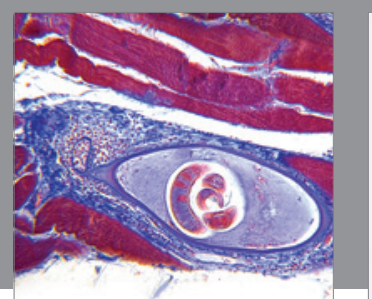

Gastroenterology Research and Practice
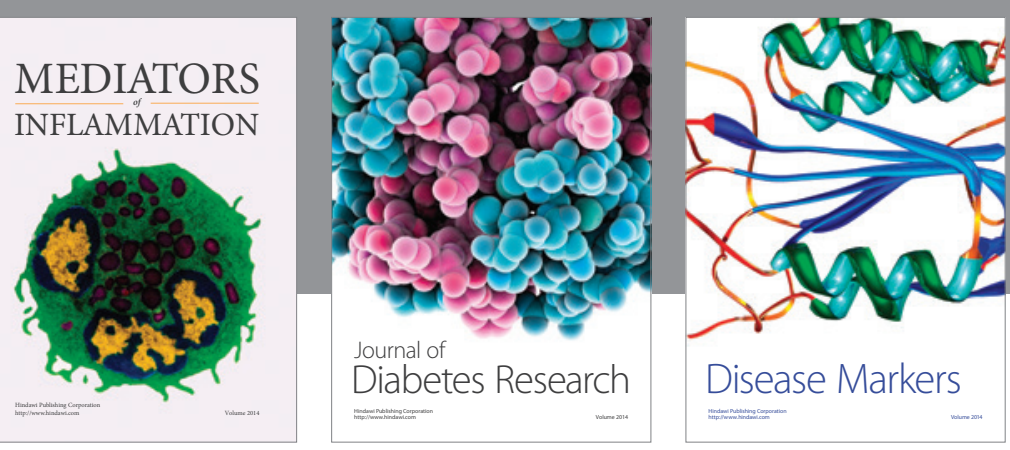

Disease Markers

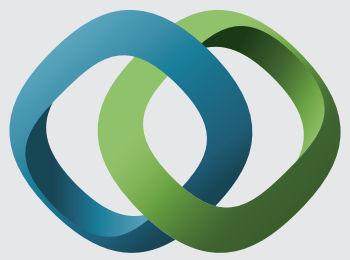

\section{Hindawi}

Submit your manuscripts at

https://www.hindawi.com
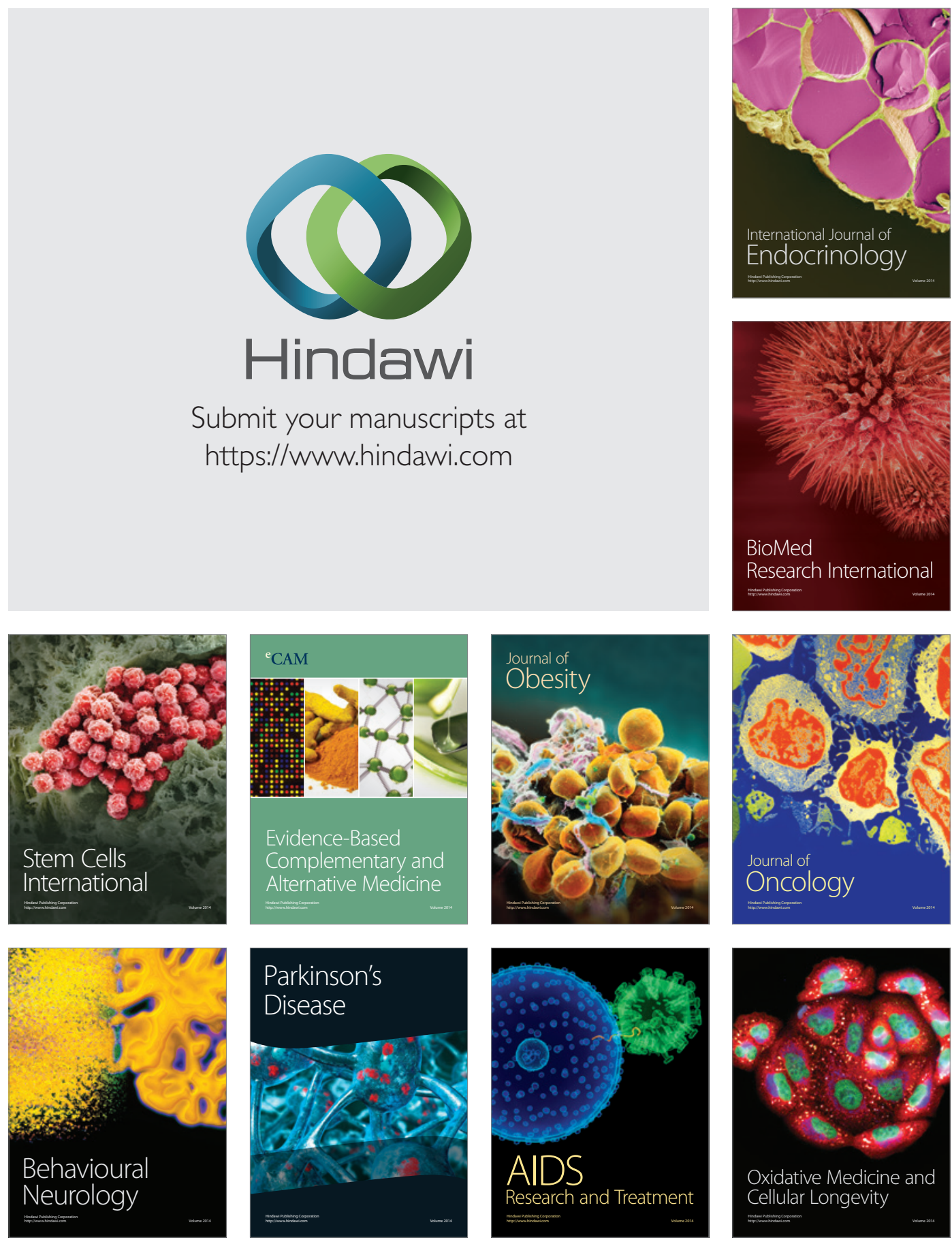